\title{
Efeitos de Modelagem do Comportamento Verbal e de Instruções sobre o Comportamento de Encaixar Peças
}

\author{
Maria Regina Cavalcante ${ }^{1}$ \\ Mariana Pinotti Carrara ${ }^{2}$ \\ Universidade Estadual Paulista Júlio de Mesquita Filho - Campus de Bauru
}

\begin{abstract}
RESUMO - Pesquisas têm demonstrado diferenças nos efeitos dos comportamentos verbais modelado e instruído sobre o comportamento verbal e não-verbal. Este estudo investigou efeitos da modelagem do comportamento verbal e das instruções sobre o comportamento verbal (falar sobre encaixar peças) e o não-verbal (encaixar peças azuis e vermelhas, grandes e pequenas e quadradas e circulares) de 10 crianças, entre 8 e 9 anos de idade. A coleta de dados foi realizada em duas condições com cinco participantes. Condição 1: modelagem do comportamento verbal. Condição 2: apresentação de instruções para o comportamento não-verbal. Quando ocorreu a modelagem do comportamento verbal foram observadas mudanças correspondentes no comportamento não-verbal. As instruções produziram imediata adesão do comportamento não-verbal e, na sequiência, o desempenho foi alterado. Esses dados reafirmam a importância de ampliar o conhecimento dos efeitos da modelagem do comportamento verbal e das instruções sobre o comportamento de crianças em jogos como o utilizado nesta pesquisa.
\end{abstract}

Palavras-chave: comportamento governado por regras; comportamento verbal modelado; comportamento não-verbal instruído.

\section{Effects of Verbal Behavior Shaping and of Instructions about Setting Pieces Behavior}

\begin{abstract}
Research has been shown differences in effects of shaped and instructed verbal behaviors on verbal and nonverbal behavior. This study investigated the effects of verbal behavior shaping and of the instructions about verbal behavior (to talk about setting pieces) and the nonverbal behavior (to set blue and red, large and small, and square and circular pieces) of 10 children, between 8 and 9 years old. The data collection was made in two conditions with five participants. Condition 1: verbal behavior shaping. Condition 2: presentation of instructions for nonverbal behavior. When verbal behavior shaping occurred, correspondent changes at the nonverbal behavior were observed. Instructions produced immediate nonverbal behavior adhesion and the performance was altered. These data reaffirm the importance of expanding the knowledge about the effects of verbal behavior shaping and of instructions about children's behavior in games like the one used in this research.
\end{abstract}

Key words: rule-governed behavior; shaped verbal behavior; instructed nonverbal behavior.

O repertório comportamental dos indivíduos depende de suas experiências de vida e das consequiências diretas de suas ações no ambiente, bem como as descrições verbais apresentadas pela comunidade têm um papel fundamental na constituição das características peculiares a cada ser humano.

As descrições verbais apresentadas pela comunidade são denominadas regras ou instruções, pois descrevem para um indivíduo como se comportar em determinada situação e as possíveis conseqüências de suas ações. Por exemplo: uma criança pode aprender a encaixar peças de um jogo de lego em função dos brinquedos produzidos e das brincadeiras que oportunizam, ou pelas orientações fornecidas pela mãe e/ou pela demonstração da construção de brinquedos e

1 Endereço: Universidade Estadual Paulista Júlio de Mesquita Filho, Campus de Bauru, Av. Luiz Edmundo Carrijo Coube, 14-05, Vargem Limpa, Bauru, SP, Brasil, 17033-360. E-mail: mregina@fc.unesp.br

2 Trabalho desenvolvido com auxílio da FAPESP (bolsa institucional de Iniciação Científica). brincadeiras que a mãe realiza. Assim, se a criança aprende a encaixar as peças do jogo em função das consequiências que suas ações produzem, esse comportamento foi modelado pelas contingências. Se ela aprende a montar brinquedos em função das orientações da mãe, seu comportamento foi instalado por regras.

Skinner (1969/1980) afirmou que comportamentos modelados por contingências são comportamentos mantidos diretamente pelas relações entre a resposta e suas conseqüências e comportamentos governados por regras são comportamentos que ocorrem sob controle de estímulos discriminativos verbais.

Algumas investigações (Albuquerque, Paracampo \& Albuquerque, 2004); Albuquerque \& Silva, 2006; Catania, Lowe \& Horne, 1990; Catania, Matthews \& Shimoff, 1982; Cavalcante, 1999; Cavalcante, Barreiros, Rosin, Villas Boas \& Salina, 2002; Neef \& col.s, 2004; Northup, Kodak, Grow, Lee \& Coyne, 2004; Paracampo, 1991; Shimoff, Matthews \& Catania, 1986) têm sido desenvolvidas para estudar experimentalmente os efeitos de regras/instruções sobre o que as pessoas falam e fazem. 
Catania e cols. (1982) estudaram as diferenças entre comportamento verbal modelado e instruído por meio de um experimento em que sujeitos adultos deveriam aprender a pressionar dois botões de acordo com diferentes esquemas de reforçamento pela modelagem ou instrução de seus comportamentos verbais. O procedimento consistiu de duas fases que se alternavam ao longo do estudo. Numa fase, os sujeitos foram expostos diretamente aos esquemas e na outra (período de palpites), eles deveriam completar, por escrito, sentenças acerca do seu desempenho em relação aos botões. Para a modelagem do comportamento verbal, o experimentador atribuía de 0 a 3 pontos conforme a resposta dada. Para alguns sujeitos, as respostas verbais modeladas ou instruídas eram discrepantes das contingências programadas para o comportamento de pressionar. Os autores observaram que metade dos sujeitos, cujo comportamento verbal foi modelado, apresentou taxas diferenciais de respostas nos botões, isso é, responderam de acordo com o esquema de reforçamento descrito verbalmente, mesmo quando as contingências programadas para o comportamento de pressionar foram alteradas. Alguns sujeitos, cujo comportamento verbal foi instruído, apresentaram taxas de respostas consistentes com a instrução, outros apresentaram taxas consistentes com o esquema em vigor e para outros não foi observada relação entre as taxas de pressão e o comportamento verbal. Os resultados sugerem que o comportamento verbal freqüentemente produz efeitos sobre o comportamento não-verbal subseqüente, principalmente quando o comportamento verbal é modelado.

Ainda preocupados com a investigação sobre os efeitos de comportamento verbal sobre comportamento não-verbal, Catania e cols. (1990) estudaram os efeitos da modelagem do comportamento verbal sobre o comportamento de pressionar figuras em uma tela sensível de acordo com diferentes esquemas de reforçamento de sete crianças com idades variando entre 4 e 5 anos. Diferentemente de Catania e cols. (1982), neste estudo o procedimento de modelagem do comportamento foi realizado por meio de um boneco que fazia perguntas às crianças sobre o funcionamento do jogo e apresentava as conseqüências para as verbalizações das crianças que se aproximavam da resposta correta. A modelagem do comportamento verbal ocorreu para três crianças. Destas, uma apresentou correspondência entre comportamento verbal e não-verbal até o final do experimento e duas apresentaram correspondência durante parte do experimento. Os autores apontaram dificuldades no procedimento de modelagem do comportamento verbal em função de variações ocorridas no procedimento e na inabilidade do experimentador em modelar o comportamento verbal das crianças. Apesar dessas dificuldades, quando a modelagem ocorreu, houve mudanças no comportamento não-verbal.

Cavalcante (1999) também investigou o papel das instruções e das contingências sobre o comportamento verbal e não-verbal de crianças de 5 e 6 anos. Diferentemente dos estudos anteriormente descritos, a autora pesquisou o desempenho das crianças em uma tarefa que se aproxima daquelas que elas costumam desenvolver no cotidiano (jogo de encaixar peças de várias cores, formas e tamanhos em furos de um tabuleiro) de acordo com critérios previamente programados para reforçamento tanto do comportamento verbal como do comportamento de encaixar peças. Os resultados indicaram que apenas uma das nove crianças, sob a Condição Com Instrução, encaixou peças de acordo com a instrução até o final do jogo. Das crianças sob a Condição Sem Instrução (23 participantes), apenas uma apresentou desempenho compatível com as contingências programadas para o comportamento de encaixar. De acordo com a autora, esses resultados são diferentes daqueles obtidos na literatura da Análise Experimental do Comportamento consultada porque os procedimentos também o foram, especialmente no sentido de que, por um lado, foram utilizadas tarefas similares às que os participantes realizam no cotidiano e, por outro, houve pequenas diferenças na condução do procedimento. Os procedimentos convencionalmente utilizados fazem uso de tarefas com formatos distintos envolvendo diferentes topografias em relação às atividades do cotidiano de crianças com idades entre 5 e 6 anos. Esses procedimentos consistem na instalação de um padrão de desempenho de acordo com um esquema de reforçamento, na apresentação de instruções ou modelagem de comportamento verbal que descreve desempenho apropriado ao esquema e exposição do desempenho ao esquema de reforçamento descrito verbalmente. Após a estabilidade do desempenho, são promovidas alterações nas instruções e/ou contingências para testar o efeito de instruções. Neste estudo, a pesquisadora não utilizou qualquer critério de estabilidade do desempenho e o procedimento não possibilitou a modelagem do comportamento de encaixar peças de acordo com os critérios selecionados para conseqüenciação. Por isso, a autora sugeriu que se continuasse investigando os efeitos de instruções e contingências em tarefas semelhantes, com novas variações no procedimento de coleta de dados. A autora sugeriu: a) a manutenção da tarefa de encaixar e a utilização de apenas duas propriedades de cada dimensão das peças (peças azuis e vermelhas, grandes e pequenas, quadradas e circulares) em vez de três propriedades de cada dimensão para minimizar a complexidade da tarefa e possibilitar a modelagem do comportamento de encaixar peças; b) o estabelecimento de 40 tentativas consecutivas conseqüenciadas ou não como critério de estabilidade do desempenho e c) o critério de 1 hora para finalizar a sessão, caso o critério de estabilidade do desempenho não fosse atingido.

Considerando as sugestões de alterações no procedimento sugeridas por Cavalcante (1999) e analisando a importância de investigar os efeitos de instruções e contingências em contexto que se aproximam do cotidiano, Cavalcante e cols. (2002) pesquisaram o comportamento de encaixar peças de oito crianças. As quatro crianças da Condição Sem Instrução apresentaram desempenho sensível às contingências programadas, durante todo o jogo. Das quatro crianças da Condição Com Instrução, três aderiram à instrução durante todo o jogo e uma apenas em parte do jogo. Independentemente da programação de conseqüências, verificou-se que as crianças encaixavam as peças em seqüências (seqüências de peças quadradas, de peças azuis, etc) como se estivessem "brincando" com as peças ou mesmo experimentando outras atividades que a natureza do jogo possibilitava. Esses dados sugerem que as contingências programadas não exerceram controle sobre o comportamento das crianças durante o jogo, isso é, independentemente das conseqüências programadas 
o comportamento de encaixar ocorria em função das possibilidades que o jogo oportunizava.

Considerando a importância de continuar investigando o desempenho de crianças em tarefas próximas daquelas desenvolvidas no cotidiano e buscando ampliar a compreensão dos efeitos de instruções sobre o comportamento não-verbal, este estudo investigou os efeitos da modelagem do comportamento verbal e das instruções sobre o comportamento verbal (de falar sobre o que deveria ser feito na tarefa de encaixe) e sobre o comportamento não verbal (encaixar peças em furos de um tabuleiro) de 10 crianças, entre 8 e 9 anos de idade, em um jogo de encaixe semelhante aos brinquedos utilizados no cotidiano.

\section{Método}

\section{Participantes}

Após a aprovação do projeto de pesquisa pelo Comitê de Ética em Pesquisa da Faculdade de Ciências da Universidade Estadual Paulista - UNESP/Bauru, e após o recebimento de autorização dos dirigentes da escola em que a pesquisa foi executada (Escola Estadual de Ensino Fundamental de um Município do Estado de São Paulo), realizou-se o levantamento das crianças com as idades esperadas para a pesquisa (8 e 9 anos), por meio de listagens dos alunos fornecidas pela escola.

Participaram desse estudo 10 crianças. Quanto ao sexo, idade e escolaridade dessas crianças, cada grupo foi assim composto: Grupo 1 - P01 (sexo feminino, 9 anos, $3^{\mathrm{a}}$ série), P02 (sexo masculino, 8 anos, $2^{\mathrm{a}}$ série), P03 (sexo feminino, 9 anos, $3^{\text {a }}$ série), P04 (sexo masculino, 9 anos, $3^{\mathrm{a}}$ série), e P05 (sexo feminino, 8 anos, $2^{\mathrm{a}}$ série); Grupo 2 - P06 (sexo masculino, 9 anos, $3^{\mathrm{a}}$ série), P07 (sexo feminino, 9 anos, $3^{\mathrm{a}}$ série), P08 (sexo masculino, 9 anos, $3^{\mathrm{a}}$ série), P09 (sexo feminino, 8 anos, $2^{\mathrm{a}}$ série), P10 (sexo masculino, 8 anos, $2^{\mathrm{a}}$ série).

Para participar da pesquisa as crianças deveriam demonstrar discriminação das cores azul e vermelha, das formas do círculo e do quadrado e dos tamanhos grande e pequeno.

\section{Materiais e Equipamentos}

O material principal empregado consistiu em um jogo de encaixe contendo um tabuleiro de madeira medindo $1 \mathrm{~m}$ x $1 \mathrm{~m}$ com 100 furos para o encaixe de peças de madeira coloridas. As peças a serem encaixadas somavam um total de 280, divididas em dois subconjuntos de 140 peças segundo a dimensão forma (com duas propriedades: 140 quadrados e 140 círculos); cada um desses subconjuntos era subdividido em dois outros subconjuntos de 70 peças de acordo com a dimensão cor (com duas propriedades: 70 azuis e 70 vermelhas) que, por sua vez, eram subdivididas de acordo com a dimensão tamanho (com duas propriedades: 35 grandes e 35 pequenas). Bolas de gude foram utilizadas para conseqüenciar as respostas de encaixar peças e as respostas verbais de descrição da tarefa. Duas vasilhas de plástico foram colocadas ao lado do tabuleiro para as crianças depositarem as bolas de gude durante o jogo. Havia também uma "lojinha" com vários brindes, tais como bolas, jogos, lápis, etc. Cada brinde continha, em local visível, um "preço", ou seja, uma etiqueta que especificava o número de bolinhas que a criança deveria ganhar durante o jogo para comprá-lo. O registro manual dos dados foi feito em um protocolo no qual foram anotados os dados de identificação da criança, número da sessão, procedimento ao qual foi submetida, data da coleta, número das fitas e hora do início e término da sessão. Cada tentativa foi representada por um número $(1,2,3 \ldots)$ e cada propriedade das dimensões (forma, tamanho e cor) por uma letra ( $Q$ para quadrado e $\mathrm{C}$ para círculo; $\mathrm{G}$ para grande e $\mathrm{P}$ para pequeno; A para azul e V para vermelho), como por exemplo: 1. QAG (quadrado, azul, grande).

\section{Observação e registro dos dados}

As sessões de coleta de dados foram desenvolvidas por duas pesquisadoras: uma executou o procedimento e a outra realizou o registro manual dos dados. Para garantir maior fidedignidade dos resultados, as sessões também foram filmadas e gravadas em fitas cassete. Após cada sessão de coleta de dados, a pesquisadora assistia às fitas e fazia as correções necessárias no registro manual.

\section{Procedimento de Coleta de Dados}

Foi objeto de observação o comportamento de encaixar peças nos furos do tabuleiro e o comportamento verbal de descrição da tarefa. Previamente à coleta de dados, foi encaminhado um documento aos pais das crianças descrevendo em linhas gerais a pesquisa e solicitando autorização para que estas pudessem participar. A pesquisa foi realizada na própria escola dos participantes e a coleta de dados foi realizada em uma única sessão para nove crianças e em duas sessões para um dos participantes. A pesquisadora buscava o participante em sua sala de aula e o acompanhava até outra sala da mesma escola, na qual os materiais da pesquisa já estavam organizados e onde a observadora os aguardava. Nesse trajeto a pesquisadora fazia perguntas sobre os jogos de que a criança gostava e quais ela conhecia, bem como explicava que ela iria participar de um jogo. Esse procedimento foi adotado com o objetivo de estabelecer o "rapport" e familiarizar a criança com a tarefa. Ao entrar na sala de coleta de dados, a pesquisadora apresentou a observadora para a criança, mostrou a filmadora e o gravador e fez a apresentação da "lojinha", conforme a descrição a seguir:

Eu trouxe você aqui para nós brincarmos de um jogo. No jogo
nós temos esta "lojinha" com vários brinquedos. Estes brinque-
dos podem ser comprados com bolinhas de gude como estas
aqui (a experimentadora mostrou três bolinhas para a criança).
Por exemplo, esta bola vale 30 bolinhas de gude. Este quebra-
cabeça vale 50 bolinhas de gude. Durante o jogo você poderá
ganhar muitas bolinhas de gude e, no final, poderá vir aqui na
"lojinha” e comprar brinquedos com suas bolinhas de gude.
Quanto mais bolinhas de gude você ganhar, mais brinquedos
você poderá comprar. Entendeu?

Em seguida, foi solicitado à criança que explicasse como deveria proceder para comprar os brindes expostos na "lojinha”. Quando o participante não descreveu o procedimento 
de acesso aos brindes de maneira correta, a experimentadora repetiu a instrução até que a criança fizesse a descrição correspondente com a instrução apresentada. Em seguida, a experimentadora e a criança se dirigiram à mesa na qual estavam colocados o tabuleiro, as peças e as duas vasilhas de plástico. Ao iniciar a sessão, a pesquisadora pediu à criança que encaixasse algumas peças nos furos do tabuleiro para verificar se esta apresentava coordenação motora suficiente para a realização da tarefa. Enquanto a criança estava encaixando as peças, a pesquisadora fez perguntas com o objetivo de verificar se apresentava discriminação dos tamanhos, formas e cores das peças. Em seguida, a pesquisadora convidou a criança a retirar, junto com ela, as peças encaixadas e apresentou, por meio do gravador, a seguinte instrução:

Nesta brincadeira você vai ter que encaixar estas pecinhas nos furos deste tabuleiro. Quando você acertar vai ganhar uma bolinha de gude. Você tem que descobrir que peça você deve encaixar para ganhar bolinhas.

Em seguida foi solicitado à criança que explicasse o que deveria fazer no jogo. Quando a criança não descreveu a tarefa de maneira correta, a experimentadora apresentou a gravação da instrução novamente, até que ela conseguisse descrevê-la corretamente. Em seguida, o jogo foi iniciado de acordo com o procedimento programado para a Condição 1 ou 2 e o gravador foi acionado para registrar os comportamentos verbais da experimentadora e da criança. Vale lembrar que, como o tabuleiro possuía 100 furos, após o encaixe de 100 peças, era preciso que participante e pesquisadora as retirassem do tabuleiro para que fosse possível dar continuidade ao jogo. Como não foi possível evitar a comunicação entre as crianças durante a coleta de dados, foram programadas dimensões e propriedades diferentes para a conseqüenciação do comportamento verbal e do comportamento de encaixar para cada criança.

\section{Condição 1: Comportamento Verbal Modelado}

\section{Fase 1 - Modelagem do comportamento verbal}

Após a criança descrever a tarefa corretamente, o jogo foi iniciado, realizando-se o procedimento de conseqüenciação do comportamento de encaixar de acordo com o critério selecionado. A dimensão selecionada para conseqüenciação foi determinada previamente e aleatoriamente para cada criança; no entanto, a propriedade da dimensão foi escolhida com base na primeira peça encaixada pelo participante. A propriedade da dimensão escolhida para conseqüenciação na Fase 1 foi sempre a que não estava presente na primeira peça encaixada pela criança, para evitar o reforçamento acidental. Todas as vezes que a criança encaixou peças de acordo com o critério programado (por exemplo: pequeno), a pesquisadora pegou uma bolinha de gude e colocou na mão da criança. Nas primeiras tentativas solicitou que ela colocasse as bolinhas dentro da vasilha de plástico.

Para realizar a modelagem do comportamento verbal da criança, a cada 10 tentativas a experimentadora interrompia a tarefa e solicitava à criança que dissesse qual era a peça que ela estava encaixando e que a experimentadora estava lhe dando bolinhas de gude de forma que a criança descrevesse qual a peça que ela estava encaixando e que possibilitava o acesso à bolinha de gude. Diferentemente do experimento de Catania e cols (1990), que utilizou um boneco para apresentar as perguntas aos participantes, neste estudo as perguntas foram feitas pela pesquisadora. A experimentadora apresentou conseqüências positivas (disse "muito bem" e colocou uma bolinha de gude na mão da criança) às respostas que se aproximavam, cada vez mais estreitamente, da resposta final desejada. Quando a criança não respondeu adequadamente, foi instruída a continuar a tarefa. Dessa forma, as respostas foram selecionadas para serem conseqüenciadas no decorrer do experimento, dependendo do desempenho de cada participante. Para a modelagem do comportamento verbal de alguns participantes houve a necessidade de continuar apresentando a questão inicial e uma questão adicional na mesma tentativa, por exemplo: "Se você não me apontasse uma por uma (peça) como você fez, como você poderia me falar?”, para só depois que a criança estivesse respondendo corretamente, retirar a questão adicional e deixar somente a questão inicial. A necessidade de se acrescentar tais questões surgiu para evitar que, em certos momentos do jogo, alguns participantes permanecessem verbalizando apenas as mesmas respostas incorretas ou apenas apontando em direção a alguma(s) peça(s) sem apresentar qualquer verbalização. Dessa forma, a introdução das novas questões teve como objetivo ocasionar a ocorrência de variabilidade na resposta dos participantes, ou seja, aumentar a probabilidade de ocorrência de verbalizações que pudessem ser consequienciadas diferencialmente. Caso apenas a questão inicial fosse apresentada pela experimentadora e as crianças permanecessem verbalizando apenas as mesmas respostas que ainda não eram a resposta final desejada, poderia ocorrer um longo período de tempo reforçando uma mesma resposta do participante. Isso poderia acarretar saciedade ou grande fortalecimento de alguma resposta que, mais tarde, não faria parte do comportamento a ser modelado. Ou mesmo, se aquelas respostas que se repetiam não fossem conseqüenciadas e não se aumentasse a probabilidade do participante emitir outras verbalizações (apresentando a nova questão), o participante também poderia permanecer muito tempo sem ganhar bolinhas de gude e parar de verbalizar.

O critério para mudança de fase foi de 55 respostas de encaixar consecutivas conseqüenciadas e a verbalização correta da tarefa em pelo menos cinco tentativas consecutivas. Nenhuma sinalização indicou para a criança a mudança de fase.

\section{Fase 2 - Verificação do efeito da modelagem do comportamento verbal}

Após a criança ter atingido o critério selecionado para finalizar a Fase 1, foi iniciado o procedimento de conseqüenciação do comportamento não-verbal e do verbal semelhante ao utilizado na Fase 1, exceto que a propriedade da dimensão selecionada para conseqüenciação foi diferente da selecionada para a Fase 1. O critério para finalização da sessão foi de 55 respostas de encaixar consecutivas conseqüenciadas e a verbalização correta da tarefa em, pelo menos, cinco tentativas consecutivas durante a Fase 2 ou 30 minutos contados a partir da mudança de fase, o que ocorresse primeiro. 


\section{Condição 2: Comportamento Não-Verbal Instruído}

O procedimento utilizado com as crianças que passaram pela Condição 2 foi semelhante ao utilizado com as crianças que passaram pela Condição 1, tanto para a Fase 1 quanto para a Fase 2, com algumas diferenças. A primeira delas se refere ao fato de que, no início da Fase 1, após a instrução geral, foi apresentada uma instrução específica que descreveu a propriedade da dimensão da peça que a criança deveria encaixar para ganhar bolinhas de gude (Exemplo: "para ganhar bolinhas de gude, você deve encaixar peças da cor azul"). A segunda diferença ocorreu no procedimento de conseqüenciação do comportamento verbal, pois nessa condição a experimentadora apresentou conseqüências (disse "muito bem" e colocou uma bolinha de gude na mão da criança) para todas as suas verbalizações, independentemente de seu conteúdo, diante da pergunta: "Qual a peça que você está encaixando e que eu estou lhe dando bolinhas?". A última diferença refere-se ao critério para a finalização da sessão: 55 respostas de encaixar peças consecutivas conseqüenciadas durante a Fase 2 ou 30 minutos contados a partir do início da Fase 2, o que ocorresse primeiro. Por fim, nessa Condição, o objetivo da Fase 2 foi verificar o efeito da instrução apresentada no início da Fase 1.

\section{Resultados}

Para a análise do comportamento de encaixar peças foram registradas as frequiências simples e acumuladas do comportamento de encaixar peças para cada criança agrupadas em blocos de 10 tentativas. Para cada participante e para a dimensão selecionada para conseqüenciação foram elaborados gráficos de curvas acumuladas. Esses dados possibilitaram verificar se o desempenho das crianças correspondeu às contingências programadas para o comportamento verbal e para o comportamento de encaixar peças e, também, se existiram diferenças no desempenho das crianças quando o comportamento verbal foi modelado e quando foi instruído. Para a análise do comportamento verbal, foram registradas todas as respostas dos participantes em cada tentativa que a experimentadora solicitou a descrição da tarefa.

Inicialmente apresentar-se-á os desempenhos referentes à Condição 1 (CVM) (Figura.1) e, em seguida, os desempenhos referentes à Condição 2 (CNVI) (Figura 2).

\section{Desempenhos das crianças submetidas à Condição 1 (CVM)}

Antes de descrever os efeitos do comportamento verbal modelado sobre o comportamento de encaixar dos participantes, vale ressaltar que a modelagem do comportamento verbal só ocorreu para duas (P01 e P04) das cinco crianças que participaram dessa condição (P01, P02, P03, P04 e P05). Para outras duas crianças (P02 e P03) não foi possível realizar a modelagem porque, já na primeira vez em que a experimentadora perguntou qual peça produzia a bolinha de gude, essas crianças responderam de acordo com o critério estabelecido para conseqüenciação. Como neste estudo a primeira solicitação era feita após 10 encaixes de peças, as crianças encaixaram peças de ambas as propriedades da dimensão programada para conseqüenciação e, em função do reforçamento diferencial, passaram a encaixar as três e quatro últimas peças, respectivamente, de acordo com a propriedade programada para conseqüenciação. Dessa forma, como a modelagem do comportamento de encaixar ocorreu antes da primeira solicitação de verbalização, a primeira verbalização dos participantes pode ter sido determinada pela exposição do desempenho motor às contingências de modelagem (reforçamento diferencial) nas 10 tentativas iniciais. A não ocorrência da modelagem do comportamento verbal para essas crianças impossibilitou a análise do efeito de seus comportamentos verbais modelados sobre seus comportamentos de encaixar peças, um dos objetivos desta pesquisa.

A criança P05 apresentou variação nas respostas verbais a cada solicitação apresentada pela experimentadora, dificultando a identificação de respostas que se aproximavam daquela programada para a conseqüenciação. Esse desempenho ilustra a dificuldade de realizar a modelagem do comportamento verbal, já apontada em estudos de Catania e cols. (1982) e Catania e cols. (1990).

No que se refere ao desempenho das crianças ao longo do experimento, tanto P01 quanto P04 iniciaram o jogo oscilando entre o encaixe de ambas as propriedades da dimensão selecionada para conseqüenciação na Fase $1 . \mathrm{Na} 10^{\mathrm{a}}$ tentativa, quando a experimentadora solicitou que descrevessem a peça que, ao ser encaixada, produzia bolinhas de gude, eles apontaram em direção ao tabuleiro. Gradativamente, a emissão dos comportamentos não-verbal e verbal de acordo com o critério programado para conseqüenciação na Fase 1 (cor azul para P01 e tamanho pequeno para P04) foi aumentando de frequiência em função do reforçamento diferencial.

Entretanto, enquanto P04 encaixou exclusivamente peças do tamanho pequeno ainda na primeira sessão, $\mathrm{P} 01$ encaixou várias peças azuis (cerca de 12 peças), uma peça vermelha e, em seguida, voltava a encaixar uma sequiência de peças azuis e assim por diante. Dessa forma, esse participante parecia "brincar" com as peças. Essa "brincadeira" permaneceu por várias tentativas, provavelmente devido ao efeito reforçador que a mesma parecia ter para o participante. Além disso, essa "brincadeira" não produzia a perda de muitas bolinhas. $\mathrm{Na}$ verdade, o participante deixava de ganhar uma bolinha de gude em um conjunto de 13 encaixes porque encaixava cerca de 12 peças azuis para uma peça vermelha. Por isso, o comportamento de "brincar" com o encaixe das peças poderia ser mantido não só pelas possíveis consequiências reforçadoras que a "brincadeira" parecia produzir, mas também pelo fato de não produzir muitas perdas de bolinhas de gude. Em função desse desempenho, P01 participou de duas sessões, porque não atingiu o critério para mudança de fase na primeira sessão.

Depois que os participantes passaram a encaixar somente peças de acordo com o critério programado para conseqüenciação, o único encaixe que não estava de acordo com esse critério foi uma peça colocada por P04 na $101^{a}$ tentativa (uma peça do tamanho grande). Para entender melhor esse desempenho é preciso relembrar como funcionava a tarefa. Após o encaixe de 100 peças, todos os furos do tabuleiro ficavam preenchidos e, para continuar o jogo, era necessário retirar todas as peças. Essa única peça do tamanho grande foi encaixada na primeira tentativa após o reinício do encai- 
xe de peças. Como na maioria dos jogos, a probabilidade das instruções se alterarem é maior no início de uma nova partida do que durante um jogo, reiniciar esse encaixe pode ter funcionado para P04 como o início de uma nova partida e a criança pode ter "arriscado" encaixar a primeira peça diferente daquelas que estava colocando até então. A peça que P04 encaixou (uma peça do tamanho grande) não estava de acordo com o critério programado para conseqüenciação nessa fase, portanto ela não recebeu bolinhas de gude. Com isso, o comportamento de encaixar peças com essa propriedade cessou e P04 voltou a encaixar peças iguais àquelas que vinha encaixando antes. Como voltou a ganhar bolinhas de gude, continuou encaixando peças com essa propriedade de dimensão até o final da Fase 1.
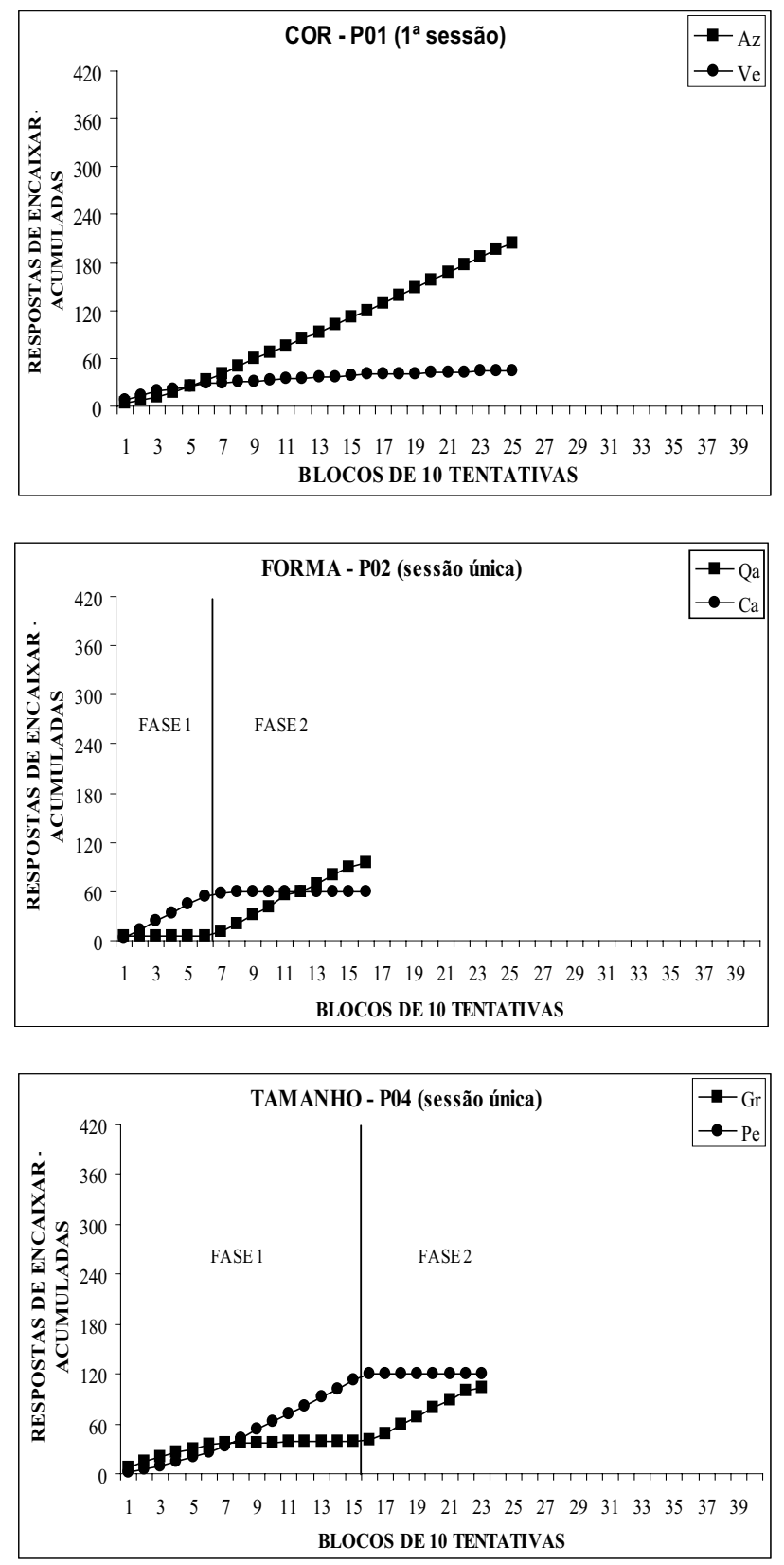

A sensibilidade às conseqüências foi característica comum do desempenho de P01 e P04 porque, após o início da Fase 2, emitiram poucas respostas de acordo com a Fase 1 e passaram, logo em seguida, a se comportar de acordo com as contingências programadas para a Fase 2 até o final da sessão.

Possivelmente o fato de essas crianças terem aprendido a falar o critério programado para a conseqüenciação do comportamento de encaixar pode ter gerado maior sensibilidade do desempenho não-verbal às conseqüências.

Quanto ao comportamento verbal de P01, a primeira verbalização da Fase 2 foi a mesma da Fase 1, assim como o comportamento não-verbal esteve também de acordo com o critério programado para a Fase 1. Mas, a partir da
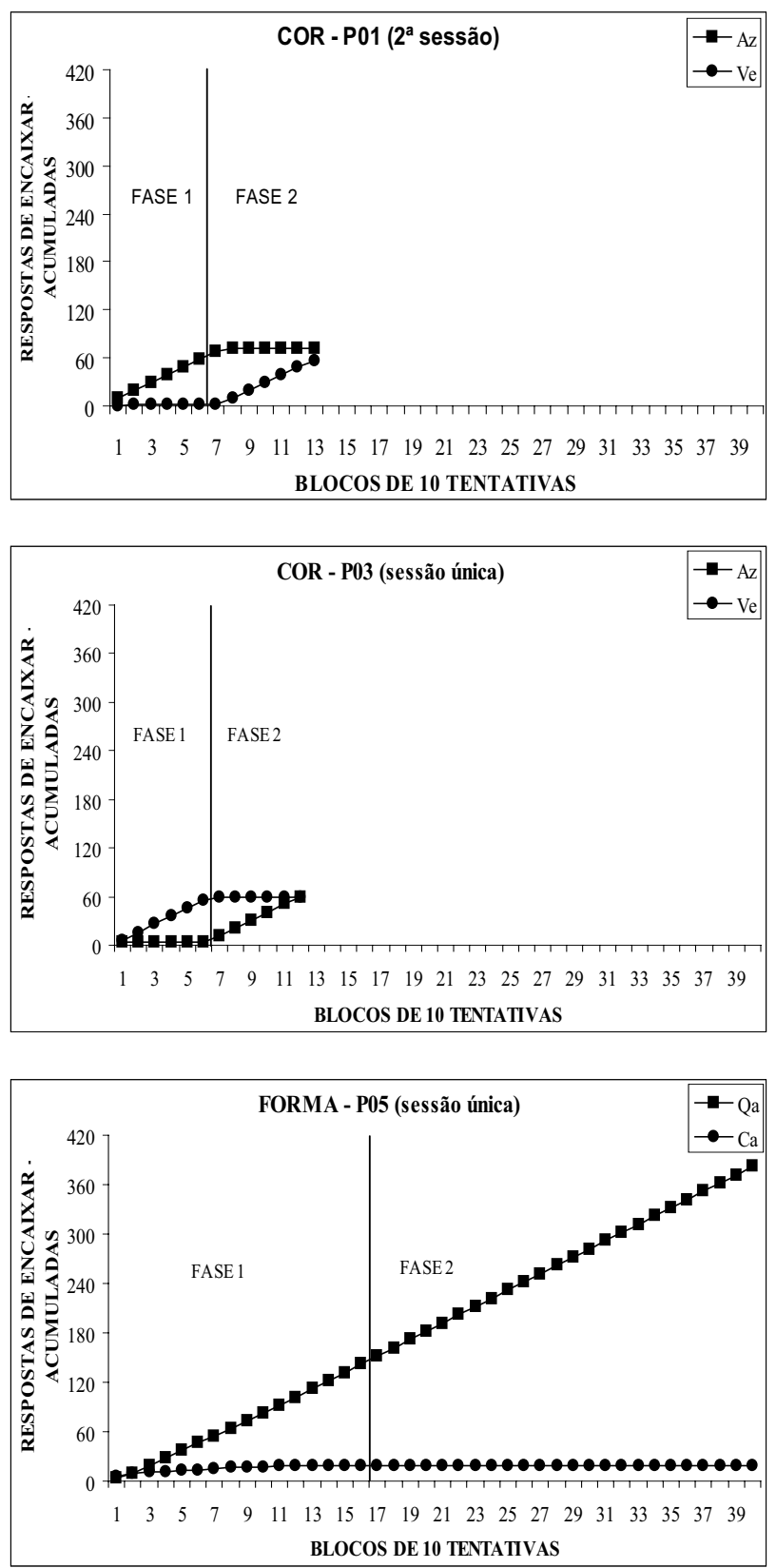

Figura 1. Número acumulado de respostas (motoras) de encaixar peças, dos participantes que foram submetidos à Condição 1 (Comportamento Verbal Modelado) no que se refere à dimensão selecionada para consequenciação do comportamento verbal e motor nas duas fases do procedimento. 
segunda solicitação, passou a verbalizar de acordo com o critério programado para a Fase 2. P04 também iniciou o jogo na Fase 2 encaixando algumas peças de acordo com a contingência programada para a Fase 1, mas diferentemente de P01 a primeira verbalização foi de acordo com o critério programado para a Fase 2.

\section{Desempenhos das crianças submetidas à Condição 2 (CNVI)}

As crianças que passaram pela Condição 2 (P06, P07, P08, P09 e P10) encaixaram peças de acordo com o critério descrito na instrução do início do jogo até o final da Fase 1. Durante toda essa fase, três crianças (P06, P07 e P10) não só
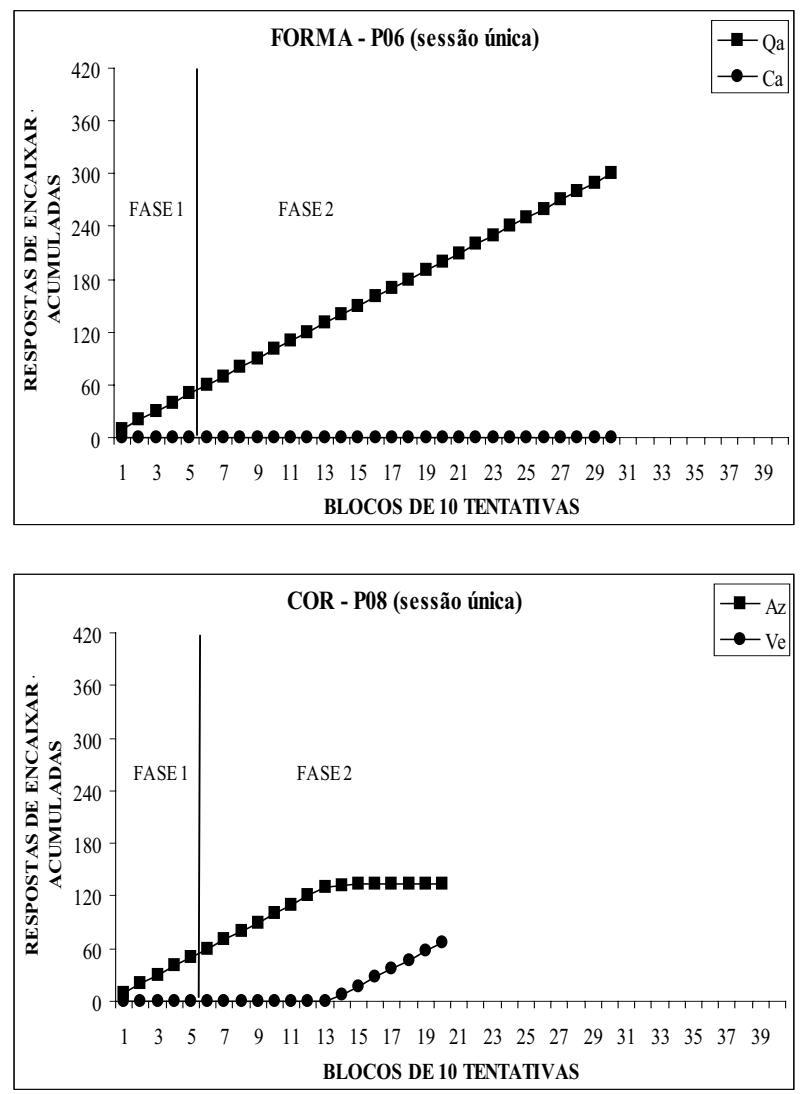

encaixaram peças mas também verbalizaram sobre a tarefa de acordo com a contingência descrita na instrução desde o início do jogo até o final da Fase 1. Entretanto, duas crianças (P08 e P09), apesar de terem encaixado peças de acordo com a contingência descrita na instrução, a verbalização sobre a tarefa foi diferente da instrução. Esses resultados indicam que, no que se refere ao comportamento de encaixar peças, todas as crianças que participaram da Condição 2 (CNVI) demonstraram adesão imediata às instruções.

O fato da primeira solicitação de descrição da tarefa ocorrer após 10 encaixes de peças dificultou a identificação dos efeitos das instruções sobre o comportamento verbal. Ou seja, desde o início do jogo até a ocorrência da primeira verbalização, todas as crianças já haviam encaixado 10
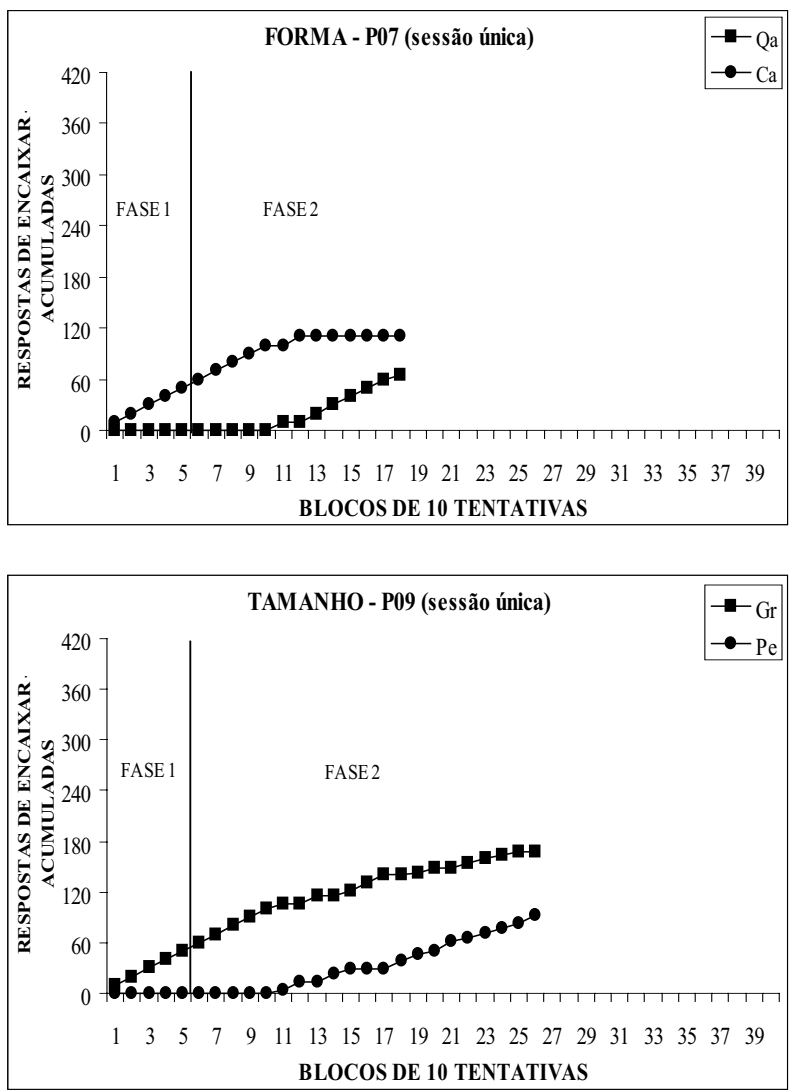

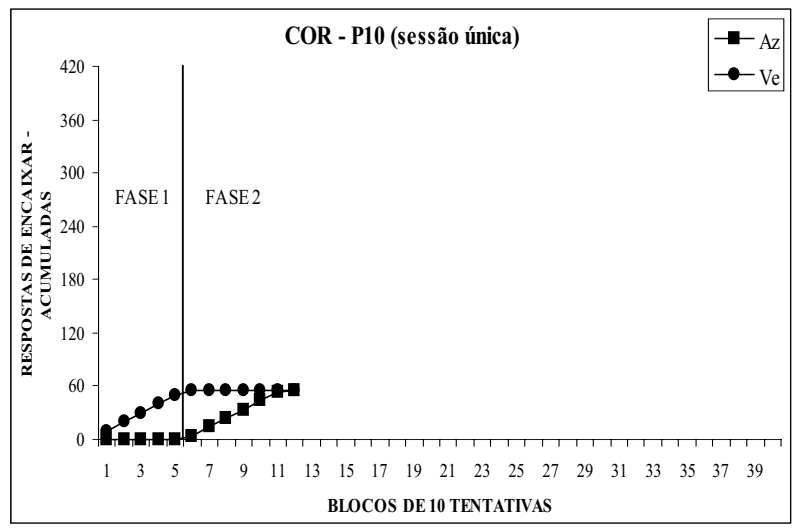

Figura 2. Número acumulado de respostas (motoras) de encaixar peças, dos participantes que foram submetidos à Condição 2 (Comportamento Verbal Instruído) no que se refere à dimensão selecionada para consequenciação do comportamento verbal e motor nas duas fases do procedimento. 
peças conforme a instrução e recebido bolinhas de gude como conseqüência para cada um desses encaixes. Assim, não se pode afirmar se a verbalização dessas três crianças, correspondentes com a instrução, ocorreu como efeito da exposição do comportamento de encaixar às conseqüências ou como efeito da instrução.

No início da Fase 2, todas as crianças continuaram encaixando peças de acordo com a Fase 1, apesar da mudança no critério para conseqüenciação. Após algumas tentativas, quatro crianças (P07, P08, P09 e P10) passaram a encaixar peças de acordo com a contingência programada para essa fase e somente uma criança manteve o desempenho verbal e não-verbal apresentado durante a Fase 1 até o final do jogo.

Dessa forma, nota-se que quatro (P07, P08, P09 e P10) das cinco crianças que participaram dessa Condição apresentaram comportamento motor sensível às consequiências. Apenas uma criança (P06), após a mudança de fase, continuou encaixando exclusivamente peças de acordo com a Fase 1 até o final da sessão, mesmo sem ganhar bolinhas de gude.

Quanto ao comportamento verbal os participantes P07, P08 e P09, no início da Fase 2, continuaram verbalizando da mesma forma que na Fase 1 e, somente após algumas tentativas, alteram suas respostas verbais. É possível que assim como o comportamento de encaixar peças desses participantes se modificou em função das conseqüências apresentadas para cada encaixe correto, o comportamento verbal se alterou em função das mudanças ocorridas no comportamento de encaixar peças. A criança P10 verbalizou de forma correta durante toda a Fase 2. Entretanto, como antes de ter sua verbalização solicitada pela primeira vez, esse participante já tinha encaixado uma peça de acordo com a Fase 1 e as quatro seguintes de acordo com a Fase 2, a análise realizada logo acima para os participantes P07, P08 e P09, no que se refere à influência do comportamento motor sobre o comportamento verbal, também parece ser válida para essa criança.

Esses desempenhos parecem indicar que, apesar de não haver reforço diferencial para o comportamento verbal nessa Condição, as consequiências que controlaram o comportamento motor de quatro participantes (P07, P08, P09 e P10) produziram efeito sobre o comportamento verbal. Assim, observa-se que o comportamento verbal desses participantes, mesmo não sendo reforçado diferencialmente, se alterou sempre que o comportamento motor (que era conseqüenciado diferencialmente) mudou.

\section{Discussão}

Catania e cols. (1982) e Catania e cols. (1990) descreveram dificuldades na modelagem do comportamento verbal dos sujeitos de pesquisa. Neste estudo também não foi possível modelar o comportamento verbal de algumas crianças. Embora na realização deste experimento tenha-se tomado o cuidado de atender a característica do procedimento de modelagem descrita por Platt e Eckerman, Hienz, Stern e Kowlowitz (citados por Catania, 1999), sobre a freqüência de apresentação de reforçadores, constatou-se a dificuldade do experimentador em, na situação de coleta de dados realizada com P05, identificar as respostas verbais que gradativamente se aproximavam da resposta programada e diante das quais deveriam ser apresentadas as consequiências reforçadoras. A realização do procedimento de modelagem do comportamento verbal exige que o experimentador tome algumas decisões rápidas no decorrer do experimento (o que não implica improvisação incompatível com planejamento experimental, mas habilidade treinada para selecionar a resposta a ser reforçada). Caso alguma delas seja realizada de maneira inadequada, toda a modelagem do comportamento verbal do participante envolvido no procedimento pode ficar comprometida.

A não ocorrência da modelagem do comportamento verbal nos casos de P02 e P03 parece ter sido determinada, principalmente, pelo procedimento de coleta de dados, que previa a descrição verbal da criança após a exposição de seu comportamento de encaixar as conseqüências por várias tentativas. Os resultados encontrados são semelhantes aos obtidos por Catania, Shimoff e Matthews (1989), que analisaram a possibilidade dos participantes estarem falando para si mesmos e gerando regras que controlariam seu comportamento não-verbal, mesmo antes da instrução ser modelada.

Para o desenvolvimento de estudos posteriores seriam necessárias algumas alterações no procedimento de coleta de dados proposto neste estudo. Sugere-se a redefinição da tentativa em que a primeira solicitação de verbalização deverá ser feita. Supõe-se que antes de qualquer encaixe ou mesmo na primeira tentativa não se constituam como os momentos mais adequados para a primeira solicitação, pois é preciso lembrar a questão inicial apresentada aos participantes ("Qual é a peça que você está encaixando e que eu estou lhe dando bolinhas?"). Era solicitado às crianças que dissessem qual peça que estavam encaixando e que a experimentadora estava lhe dando bolinhas. Assim, se essa solicitação fosse realizada antes de a criança encaixar uma peça, a questão poderia ficar sem sentido. Caso a primeira solicitação de verbalização fosse realizada após o primeiro encaixe de peças, a pergunta também se tornaria inadequada, pois a primeira peça encaixada nunca era conseqüenciada (a fim de evitar o reforçamento acidental) e, dessa forma, a criança não saberia responder qual a peça que ela encaixava e em função do quê ganhava bolinhas.

Essa análise se aplica também a crianças que passaram pela Condição CNVI, pois desde o início do jogo até a ocorrência da primeira verbalização, todas já haviam encaixado 10 peças e recebido bolinhas de gude como conseqüência para cada acerto. Três participantes dessa Condição (P06, P07 e P10) não só encaixaram peças mas também verbalizaram sobre a tarefa de acordo com a contingência descrita na instrução desde o início do jogo. Entretanto, não se pode afirmar se o fato de crianças verbalizarem de acordo com a instrução desde o início do jogo ocorreu como efeito da adesão às instruções apresentadas pelo experimentador ou como efeito da exposição ao procedimento de consequienciação do comportamento de encaixar.

No que se refere à maior ou menor facilidade para a realização da modelagem do comportamento verbal das crianças sob a Condição CVM, esta também pode estar relacionada às diferenças individuais dos participantes, pois apesar de serem crianças de idades próximas e que estudavam na 
mesma escola, cada qual pode ter passado por experiências distintas em suas histórias de vida. As diferenças no desempenho não-verbal de P01 e P04 parecem indicar que P04 estava mais sob controle das bolinhas que ganhava e P01 estava mais sob controle da "brincadeira" que criava com as peças no tabuleiro. Talvez os brindes da "lojinha" tivessem um efeito reforçador maior para $\mathrm{P} 04$ do que para $\mathrm{P} 01$, para a qual a "brincadeira" parecia ter um efeito reforçador maior. Dessa forma, a natureza da tarefa parece ter influenciado o desempenho de P01. Isso indica que, nas tarefas do cotidiano, as crianças podem agir de maneiras distintas daquelas que as pessoas esperam, até mesmo deixando de ganhar presentes e elogios para aproveitar a "brincadeira" oportunizada pela atividade que estão desenvolvendo. As crianças podem, por exemplo, não querer colorir com a cor verde as folhas do desenho de uma árvore para receber um elogio ou uma nota 10 em uma tarefa, mas preferir pintar com a cor azul em função de sua história reforçadora com essa cor ou em função do prazer que a atividade de pintar possibilita.

$\mathrm{O}$ fato de os comportamentos não-verbais de P01 e P04 estarem, provavelmente, sob controle de um aspecto diferente (tarefa ou brindes), parece ter feito com que elas precisassem de um número distinto de tentativas para passar a encaixar somente peças de acordo com as contingências programadas. Entretanto, para ambos, o comportamento de encaixar passou a ficar exclusivamente sob controle do critério programado para conseqüenciação somente após ter ocorrido a modelagem do comportamento verbal, indicando que a direção do controle, na Fase 1, foi do comportamento verbal para o não-verbal, conforme apontaram Catania e cols. (1982, 1990). Como nesses estudos, ocorreram muitas dificuldades para modelar o comportamento verbal, mas quando isso aconteceu, o comportamento não-verbal também sofreu alterações.

Depois que o comportamento de encaixar foi modelado, os participantes encaixaram somente peças de acordo com o critério programado para conseqüenciação, mas um dos participantes (P04) encaixou uma peça que não estava de acordo com esse critério na $100^{\mathrm{a}}$ tentativa. Conforme explicitado na sessão de análise de resultados, esse desempenho parece ter ocorrido em função de uma característica do procedimento deste experimento: o fato de ser preciso retirar todas as peças e recomeçar o encaixe de peças no tabuleiro quando fossem encaixadas 100 peças. Essa mudança pode ter sinalizado para a criança o início de uma nova partida do jogo. Para evitar esse tipo de influência no desempenho dos participantes, seria necessária a confecção de um outro tabuleiro com mais furos para a coleta de dados, de forma que a criança pudesse encaixar todas as peças da sessão sem precisar retirar peças no decorrer da atividade para continuar jogando.

Os participantes que passaram pela Condição CNVI encaixaram peças de acordo com a instrução, imediatamente após a sua apresentação, da mesma forma que resultados obtidos por Catania e cols. $(1982,1989)$ sugeriram que instruções determinam, com alta probabilidade, o comportamento não-verbal.

Diferentemente dos dados descritos na literatura, apenas um participante da Condição 2 (CNVI) encaixou peças e descreveu a tarefa de acordo com a instrução apresentada no início do experimento, durante as Fases 1 e 2. Para Matthews, Shimoff, Catania e Sagvolden (1977), o desempenho instalado por meio de instruções é insensível às contingências, isso é, as instruções podem desempenhar o papel de anular ou evitar o contato com as contingências de reforçamento. Entretanto, os mesmos autores afirmam que essa insensibilidade não é uma conseqüência inevitável da instrução e isso foi o que parece ter acontecido para quatro (P07, P08, P09 e P10) dos cinco participantes da Condição 2 (CNVI), pois seus desempenhos pareceram sensíveis às conseqüências programadas para o comportamento de encaixar peças.

\section{Conclusões}

A tarefa utilizada neste experimento (encaixe de peças nos furos de um tabuleiro de acordo com as dimensões forma, tamanho e cor) é de natureza diferente das tarefas descritas nas pesquisas que investigam os efeitos de regras e de contingências. Isso porque apesar de ser uma tarefa estruturada, pois consiste em encaixar uma peça em um furo, permite uma certa variabilidade de opções, já que a criança pode escolher as dimensões das peças a serem encaixadas e organizá-las de diversas formas. Além disso, a própria estrutura da tarefa pode possibilitar a ocorrência de conseqüências naturais que podem sobrepujar o efeito das instruções e das consequiências.

Dessa forma, evidencia-se a importância de se aprofundar o conhecimento acerca dos efeitos da modelagem de comportamento verbal e das instruções sobre o comportamento verbal e o não-verbal de crianças em jogos como o utilizado nesta pesquisa, pois esses, além de pouco investigados na literatura, aproximam-se das condições cotidianas vivenciadas pelas crianças em situações naturais. Este estudo permitiu verificar que é possível realizar esse tipo de investigação (efeitos da modelagem de comportamento verbal e instrução de comportamento não-verbal sobre o comportamento verbal e não-verbal de crianças) em atividades de natureza semelhante àquelas desenvolvidas no cotidiano). Além disso, é necessário aprofundar o conhecimento nessa área, principalmente pelo fato de que os resultados dessa pesquisa sugerem que a modelagem do comportamento verbal e a instrução do comportamento motor não exercem todos os efeitos freqüentemente encontrados na literatura quando o desempenho está sob uma grande variabilidade no procedimento de conseqüenciação.

\section{Referências}

Albuquerque, N. M. A de, Paracampo, C. C. P. \& Albuquerque, L. C. de (2004). Análise do papel de variáveis sociais e de conseqüências programadas no seguimento de instruções. Psicologia: Reflexão e Crítica, 17(1), 31-42.

Albuquerque, L. C. de \& Silva, F. M e (2006). Efeitos da exposição a mudanças nas contingências sobre o seguir regras. Psicologia: Teoria e Pesquisa, 22(1), 101-112.

Catania, A. C. (1999). Aprendizagem: Comportamento, linguagem e cognição. Porto Alegre: Artmed.

Catania, A. C., Lowe, C. F. \& Horne, P. (1990). Nonverbal behavior correlated with the shaped verbal behavior of children. The Analysis of Verbal Behavior, 8, 43-55. 
Catania, A. C., Matthews, B. A. \& Shimoff, E. (1982). Instructed versus shaped human verbal behavior: Interactions with nonverbal responding. Journal of the Experimental Analysis of Behavior, 38(3), 233-248.

Catania, A. C., Shimoff, E. \& Matthews, B. A. (1989). An experimental analysis of rule-governed behavior. Em S. C. Hayes (Org.), Rule-governed behavior: Cognition, contingencies, and instructional control (pp. 119-150). New York: Plenum.

Cavalcante, M. R. (1999). Dizer e fazer em uma tarefa de encaixe com crianças: Natureza da tarefa e o papel das instruções $e$ das contingências. Tese de Doutorado, Universidade de São Paulo, São Paulo.

Cavalcante, M. R., Barreiros, A. P., Rosin, A. R., Villas Boas, A. C. V. B. \& Salina, A. (2002). A relação dizer e fazer: Um estudo sobre o comportamento de crianças de encaixar peças [Resumo]. Em Sociedade Brasileira de Psicologia (Org.), XXXII Reunião Anual de Psicologia, Resumos (p. 89). Florianópolis: SBP.

Matthews, B. A., Shimoff, E., Catania, A. C. \& Sagvolden, T. (1977). Uninstructed human responding: Sensitivity to ratio and interval contingencies. Journal of the Experimental Analysis of Behavior, 27(3), 453-467.

Neef, N. A., Marckel, J., Ferreri, S., Jung, S., Nist, L. \& Armstrong, N. (2004). Effects of modeling versus instructions on sensitivity to reinforcement schedules. Journal of Applied Behavior Analysis, 37(3), 267-281.
Northup, J., Kodak, T., Grow, L., Lee, J. \& Coyne, A. (2004). Instuctional influences on analogue functional analysis outcomes. Journal of Applied Behavior Analysis, 37(4), 509512.

Paracampo, C. C. P. (1991). Alguns efeitos de estímulos antecedentes verbais e reforçamento programado no seguimento de regra. Psicologia: Teoria e Pesquisa, 7(2), 149-161.

Shimoff, E., Matthews, B. A. \& Catania, A. C. (1986). Human operant performance: Sensitivity and pseudosensitivity to contingencies. Journal of the Experimental Analysis of Behavior, 46(2), 149-157.

Skinner, B. F. (1980). Contingências do reforço: Uma análise teórica. (R. Moreno, Trad.) São Paulo: Abril Cultural. (Trabalho original publicado em 1969)

Recebido em 21.12.2004

Primeira decisão editorial em 11.10.2006

Versão final em 27.11.2006

Aceito em 28.03.2007

\section{CONGRESO DE AUTISMO Y TRANSTORNOS GENERALIZADOS DE DESARROLLO DE LA REGION CENTRO I Jornadas Santafesinas de Educación Especial}

Local: Santa Fe - República Argentina

Período: 18 a 21 de outubro de 2007

\section{Realização:}

ASTEMOC (Associación Santafesina de Terapia y Modificación de Conducta) e ALTER

(Equipo de Especialistas en Modificación de Conducta)

\section{Informações:}

cltrivisonno@hotmail.com

cltrivisonno@cablenet.com.ar 